\title{
Impact of Technology on Education during the Covid-19 pandemic in the context of Tura, West Garo Hills, Meghalaya
}

\author{
Dr. Meuller B. M. Sangma \\ Assistant Professor, Don Bosco College, Tura, Meghalaya
}

\begin{abstract}
It was the spring year 2020 which had really disrupted the normalcy in the lives of the globe. The tragic year filled the peaceful atmosphere with a very small but new effective organism known as novel coronavirus which had given a halt to the economy, trade and commerce, technology and education of the world. Half of the population of the globe was affected by this virus thereby leading to the unexpected deaths of dear and near ones.

Most of the educational institutes in Meghalaya were unprepared for digital learning. Despite the challenges in education during the lockdown period, paradigm shift from offline learning to online learning took place. The rapid transition from offline learning to online learning could be achieved by means of science and technology. The traditional classroom confined to four walls with desks and benches, blackboards, whiteboards and textbooks are drastically replaced by technology. Needless to say that technology has impacted positively and negatively the lives of students and teachers.

This paper aims to investigate the Impact of technology on education during the COVID-19 pandemic in the context of Tura, Meghalaya, focusing on teaching and learning imparted online.
\end{abstract}

Keywords: Technology, Education, Pandemic

\section{INTRODUCTION}

The educational system in India in general and Meghalaya in particular mostly follow conventional methods of teaching. When the nationwide lockdown was declared, it gave a sudden jerk to the flow of education creating tremendous impact on the students as well as teachers. Initially, the people of the world were unable to adjust to the corona pandemic but gradually people got themselves accustomed to the situation and started to adapt to new life situations. Though people have undergone many crises, problems and difficulties in all the perspectives yet the most affected one I would say is Education. Literally speaking, education is the modification of human behavior. Education shapes and moulds the behavior of the students. Before the lockdown in the country, students could avail their education according to the conveniences of the society, community or region. The mode of teaching was also simple. But in the year 2020, education for the students especially in the remote rural regions was a very challenging task as the poorest students are affected the most by the closing of institutions during the pandemic. Thus it has become more complex. Hence the learning experiences and the behavior of the students continued to be moulded via technology.

The pandemic has compelled the nature of teaching and learning to embrace online learning employing various methods of technology but access to electronic devices became the main hurdle.

\section{OBJECTIVE}

The primary objective of this paper is to obtain the opinions of students of Tura, West Garo Hills, Meghalaya studying in various classes by employing technology during the COVID-19 pandemic.

\section{METHODOLOGY}

For this purpose, a questionnaire on "Impact of technology on education during the COVID-19 pandemic" was prepared in the Google Form and the link was sent in the WhatsApp group. The sample consists mostly of college students from the recently passed out 6 Semester students, and current Third and Fifth Semester BA Students. Furthermore, evaluating the impact of using technology in education during the COVID-19 pandemic. This paper considers some factors such as faculty teaching tools, and student satisfaction in learning and assessment, and how COVID-19 pandemic affects the teaching and learning process. It is also noted that the psychology of the students in welcoming the online mode of learning or the acceptance of the students towards technology centred learning are addressed. 
Vol. 10, Issue 10, October 2021

DOI: $10.17148 /$ IJARCCE.2021.101004

\section{FINDINGS AND DISCUSSION}

The responses obtained for the questionnaire was analyzed and discussed as given below:

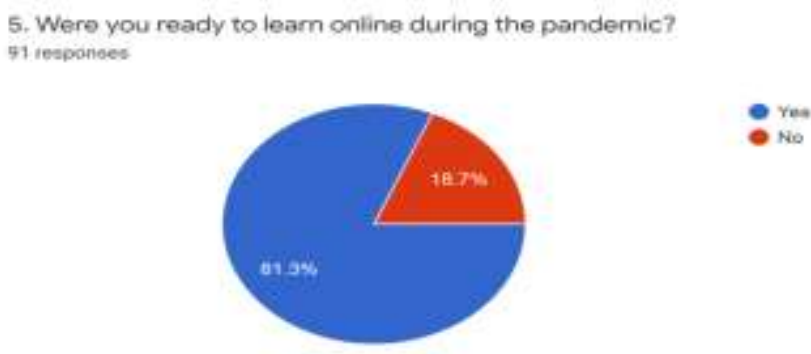

Fig. 1: Readiness to learn online during pandemic

Students though vulnerable to stress and the burdens of pandemic, yet their desire, their readiness and the willingness to keep learning never ceased. Many students lack adequate ICT literacy skills but Figure 1 indicates that 81.3 percent of the students showed their readiness to learn during the pandemic. Once they are completely equipped with the required mobile devices, the excitement and the joy of learning through the usage of technology could not stop them from exploring many things and discovering many innovative ideas.

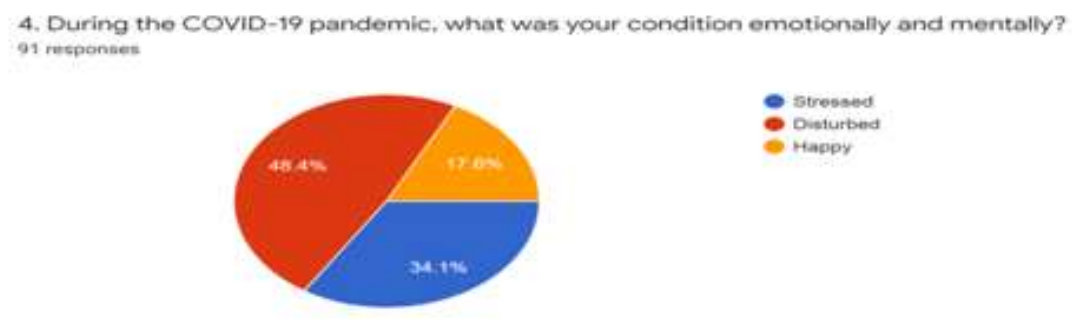

Fig. 2: Emotional and mental condition of students during pandemic

Though the students showed their readiness to learn online yet 48.4 percent of students were mentally and emotionally disturbed and 34.1 percent was mentally stressed as reflected in Figure 2 above. This indicates that they were psychologically unstable and unprepared for their online learning. Anxiety among students occurs during the lockdown because everyone was required to stay at home and all teaching and learning platforms took part virtually. Students' lost connection with human presence (Nasir, 2020) therefore it affects them mentally and emotionally.

Citing the examples in the context of my region, Tura, Meghalaya, the education scenario during the lockdown was not impressive. There were many hurdles in facilitating the students' learning via online platform as 85.7 percent of the students are from a mediocre economic family which could be seen from the Figure 3 below.

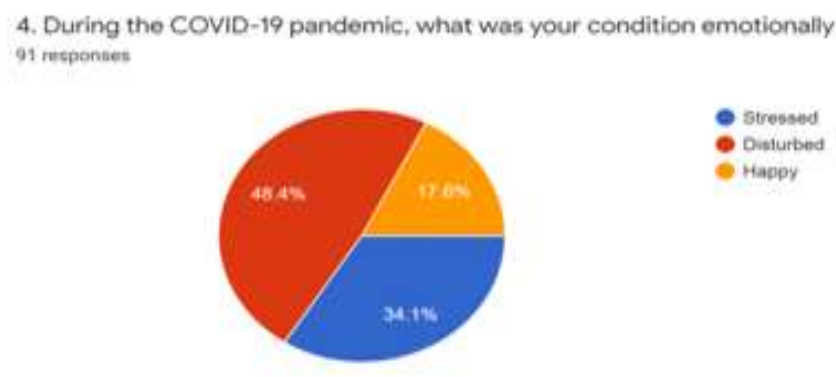

Fig. 3: Socio-economic status of students

For online learning, electronic devices and gadgets such as android mobile phones, laptops, tablets are minimum requirements. There are few colleges which could really provide online learning to students. Thanks to Technology which introduced me especially to deliver lectures and content presentations through Google Classroom, Google Meet, WhatsApp, Mentimeter, Graphic Tablets etc. These apps and platforms helped me interact with students successfully. Introducing simple animations during their virtual classes to seek their attention and interest with the help of 
Mentimeter made the students really attentive and curious and enjoy learning and hence the attention span of the students was achieved as is reflected in the Figure 4 below.

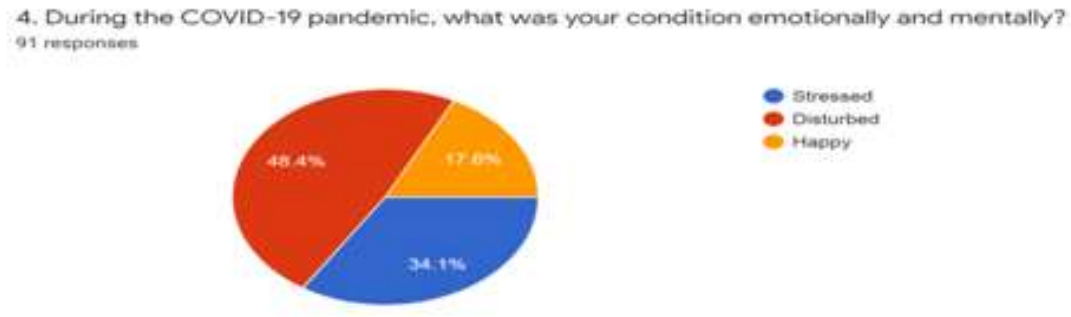

Fig. 4: Enjoyment during online classes

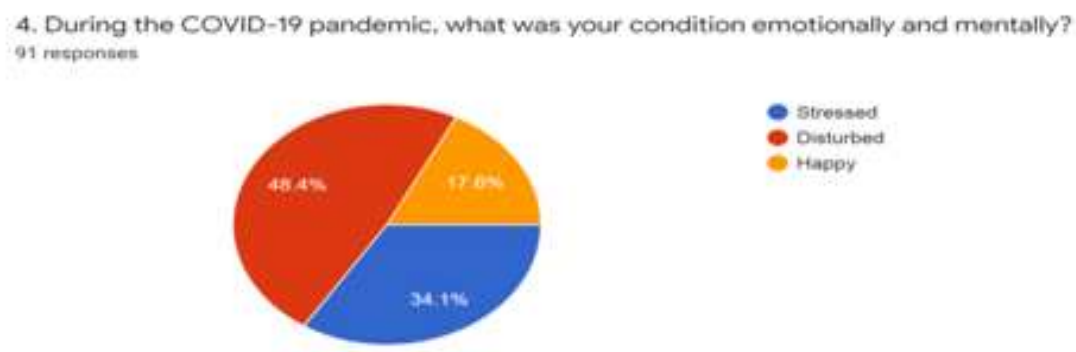

Fig. 5: Google Meet experience

33.3 percent students had a good experience in using Google Meet, 28.9 percent and 22.2 percent students respectively had an excellent experience in Google Meet as depicted in Figure 5 and other tasks such as presentation of class seminars.

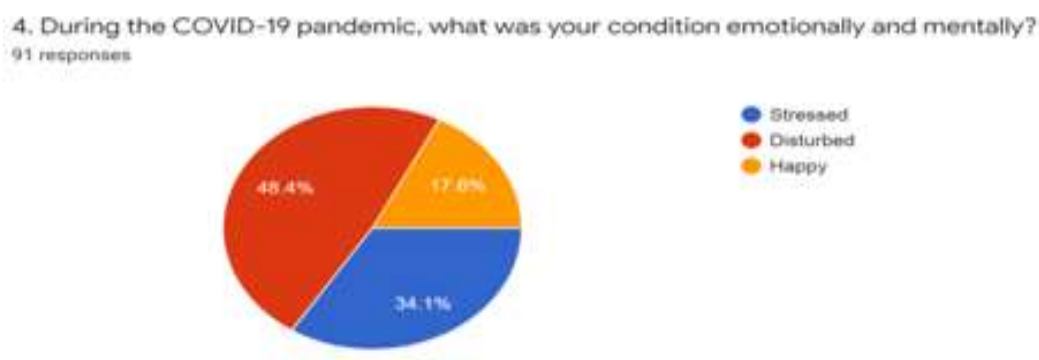

Fig. 6: Google Classroom experience

Assignments on various topics for various semesters are assigned in the Google Classroom, Tests are conducted using the Google Forms and Google Classroom as the students found it user friendly which has been reflected in the Figure 6 above. Study materials are also provided in the Google Classroom. Semester examinations are conducted in blended mode i.e, online and offline. Technology and the internet has immensely contributed to the future career of our students as it has made learning more accessible. Despite many challenges everything became possible and was successfully achieved.

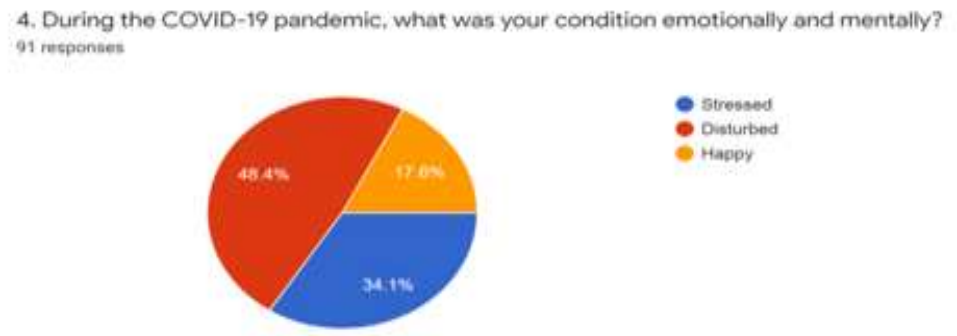

Fig. 7: Purchasing of new mobile phones 
Citing the instances of the use of technology in education with special reference to Meghalaya in general and Tura in particular, was undoubtedly a dream within a dream. To continue with the teaching and learning during the lockdown period, it was indeed very tough for the students to attend their classes online for few specific reasons such as poor internet connection, lack of availability of android phones, establishment of suitable place, lack of support from economic circumstances parents etc. which has been reflected in Figure 7. Though 64.8 percent students could equip themselves with necessary devices, yet another 35.2 percent students could not obtain the gadgets thereby creating imbalance in imparting online classes. There was another serious problem posed before the parents and the guardians as they are not in a position to render technical guidance and assistance to prepare their children or their wards for online lessons adequately.

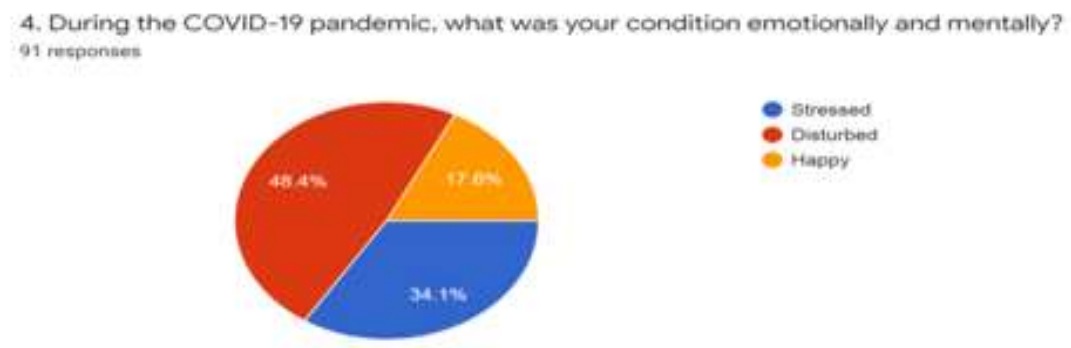

Fig. 8: Internet connectivity

When the attendance of students was checked through Google Classroom it was found that some of the students missed their classes. When the investigator inquired their reason it was due to lack of proper internet connectivity they could not attend their classes. It is seen from Figure 8 that 46.2 percent of the students had poor internet connectivity. It is suggested that the state government should take immediate steps in assisting the students with poor internet connectivity so that students do not miss their classes and can achieve better interaction with the teachers as well as with their peer friends.

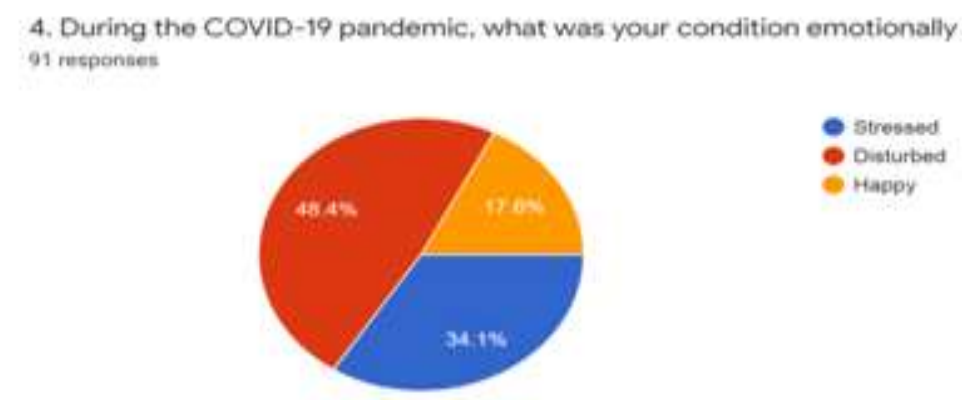

Fig. 9: Google Classroom and Google Meet after covid 19

Students encountering trouble in accessing the online learning are dissatisfied with the ongoing teaching learning process as they could not avail the education being provided through online mode. As seen in the above Figure 9, 61.1 percent of the students are not in favour of the online mode of learning through Google Classroom and Google Meet as the abrupt transition from direct learning to virtual learning has generated intense pressure in the students as well as parents.

\section{OBSERVATION AND RECOMMENDATION}

Online learning with different online learning tools and applications is undoubtedly not going to ensure learning of students effectively but it can be instruments for teachers to keep their students continue their learning even after COVID 19 to interact and communicate via online platforms.

Though COVID 19 has created many difficulties and challenges in the lives of students, teachers and parents yet there are many ways in which technology has added a value to the student's academic achievement. It has also created in the students the desire and the passion and also the curiosity to learn. Students from higher Semesters i.e, recently passed out 6 Semester students are not only self motivated to learn but taking the benefits of such platforms they attended webinars, online meetings and discussions and discover their innate skills and dispositions. They keep accessing plenty 
DOI: $10.17148 /$ IJARCCE.2021.101004

of resources on the internet and continue to study during lockdowns as they were on the verge of completing their graduation program to obtain a positive learning outcome. Thus the achievement motivation is attained.

The dire need of the hour for the students of Tura, Meghalaya is to have proper and adequate facilities in the educational system to experience and learn in real and virtual classrooms so that when unexpected times like pandemic and other consequences engulf, students will not panic instead prepare themselves to overcome any problems.

\section{CONCLUSION:}

From the overall analysis, it is understood that COVID-19 pandemic attacked the globe abruptly especially Meghalaya when most of the educational institutes were unprepared for online learning physically, mentally, emotionally and digitally. Despite the challenges in education during the lockdown period, paradigm shift from offline learning to online learning took place which has been clearly reflected in the given graphs. The rapid transition from offline learning to online learning could be achieved by means of science and technology. At the first stage of using means of technology, the teachers and the students were less familiar with various modes of online learning platforms and virtual classrooms. Teachers had to adapt to new pedagogical skills and knowledge which requires self-training. Eventually, the teachers did not lose hope and they struggled to keep in touch with students. Teachers are to be applauded and appreciated for keeping the students involved and engaged even during the hard times of pandemic.

\section{REFERENCES}

1. Nasir M.Khalid M. "The Influence of Social Presence on Students' Satisfaction toward Online Course” Open Praxis, 12, pp. 485-493, 2020

2. https://www.frontiersin.org/articles/10.3389/fpsyg.2021.656776/ful

3. https://coed.dypvp.edu.in/educational-resurgence-journal

4. https://timesofindia.indiatimes.com/

5. http://sersc.org/journals/index.php/IJAST/article/view/25414

6. https://www.ericsson.com/en/blog/2020/5/impact-of-technology-on-education

7. https://www.brookings.edu/blog/education-plus-development/2021/08/23/

8. https://www.tandfonline.com/doi/full/10.1080/2331186X.2021.1964690

9. https://onlinelibrary.wiley.com/doi/10.1002/hbe2.242

10. https://www.bgca.org/news-stories/2020/July/Teacher-Shares-Eye-Opening-Effect-of-School-Changes-and-COVID-19-on-Americas-Youth?

11. https://www.online-journals.org/index.phpand-infuse-it-into-a-current-educational-framework-1724540-2020-09-25

12. https://www.indiatoday.in/education-today/featurephilia/story/covid-19-impact-is-it-enough-to-simply-introduce-technology 